\title{
A Solitary Bronchial Papilloma with Malignant Changes
}

\author{
Yuichi Inoue, Mikio OKa***, Hiroshi IshiI, Koji Kimino*, Masao KishiKawA**, Masahiro Ito**, \\ Tetsuya Iто**, Masahiro NAKASHIMA** and Shigeru KoHNo***
}

\begin{abstract}
We describe a case of solitary papilloma of the bronchus and provide a review of 38 similar cases reported in Japan. A 70-year-old man complained of cough and sputum. Chest $\mathrm{X}$-rays and $\mathrm{CT}$ scans revealed atelectasis of the right middle lobe. On bronchoscopy, a polypoid tumor was found at the orifice of the bronchus of the right middle lobe. The tumor was histologically diagnosed as a squamous papilloma with moderate atypia. Because of elevated tumor markers and the reported high incidence of malignant changes in papillomas, the tumor was endoscopically resected by electrosurgical snare. While this procedure resulted in improvement of atelectasis, the chest $\mathrm{CT}$ taken subsequently revealed a mass adjacent to the resected polypoid tumor in the middle lobe bronchus. Percutaneous needle biopsy followed by histopathological examination confirmed the tumor to be a squamous cell carcinoma. Only three cases of malignant changes in papillomas have been previously reported in Japan. Electrosurgical snare, which allows the identification of tissue at the tumor base, should be the treatment of choice rather than YAG laser surgery.

(Internal Medicine 40: 56-60, 2001)
\end{abstract}

Key words: lung cancer, endobronchial polyp, electrosurgical snare

\section{Introduction}

Bronchial squamous papilloma, a benign tumor originating from squamous epithelial cells, accounts for $0.38 \%$ of all lung tumors (1). However, a solitary bronchial papilloma without coexistent pharyngeal papilloma is even more rare. Previous studies have suggested that this type of benign tumor is liable to be complicated by transformation to squamous cell carcinoma at its base, and it should rather be considered as a precancerous lesion (2). We treated a case of squamous papilloma located at the orifice of the bronchus of the right middle lobe, which was subsequently complicated by development of lung cancer at the base followed by invasion of the lung.

\section{Case Report}

A 70-year-old man was referred to our hospital for further examination of an abnormal shadow on the chest X-ray. He complained of productive cough and exertional dyspnea. $\mathrm{He}$ was a heavy smoker with a smoking index of 1,410 (30 cigarettes/day for 47 years). Work history included previous engagement in the production of chemical manure. Physical examination was unremarkable.

Serum tumor markers squamous cell carcinoma antigen (SCC-Ag) and cytokeratin 19 fragment marker (CYFRA) were elevated to $6.1 \mathrm{ng} / \mathrm{ml}(<1.5)$ and $5.6 \mathrm{ng} / \mathrm{ml}(<2.0)$, respectively. Pulmonary function tests showed markedly reduced forced expiratory volume in one second $\left(\mathrm{FEV}_{1.0}, 1,060 \mathrm{ml}\right)$. A large band-like shadow extending from the hilum to the right middle lung field was detected on the chest radiogram (Fig. 1). Although the past history of chest-related diseases was negative, post-inflammatory changes in the right upper lobe and bilateral pleural thickening were also evident on the chest radiogram, indicative of a possible old tuberculous lesion. The right middle lobe was atelectatic, suggesting obstruction by a tumor of the central bronchus on a computed tomogram (Fig. 2). Bronchoscopic examination performed to explore the cause of atelectasis, identified a polypoid tumor obstructing the main bronchus of the right middle lobe. The tumor was very soft and free of coating, bleeding and ulceration (Fig. 3). Histopathological examination of a biopsy material showed the papillalike tumor was composed of angiofibrous interstitium with proliferation of stratified squamous epithelium and a tendency for differentiation from the base to the superficial layer (Fig. 4A and B). Based on the clinical, bronchoscopic and histopathological findings, a provisional diagnosis of squamous papilloma with moderate atypia was made. The immunohistological study showed P53 positivity in scattered cells in the papilloma (Fig. 4C). Because of the elevated tumor markers of SCC-Ag and CYFRA, the patient was admitted to the hospital for excision of the polyp by electrosurgical snare.

From the Departments of Internal Medicine, *Surgery and **Pathology, Isahaya Insurance General Hospital, Nagasaki and $* * *$ the Second Department of Internal Medicine, Nagasaki University School of Medicine, Nagasaki

Received for publication January 13, 2000; Accepted for publication June 13, 2000

Reprint requests should be addressed to Dr. Yuichi Inoue, the Department of Internal Medicine, Isahaya Insurance General Hospital, 24-1 Eishohigashi-machi, Isahaya, Nagasaki 854-8501 


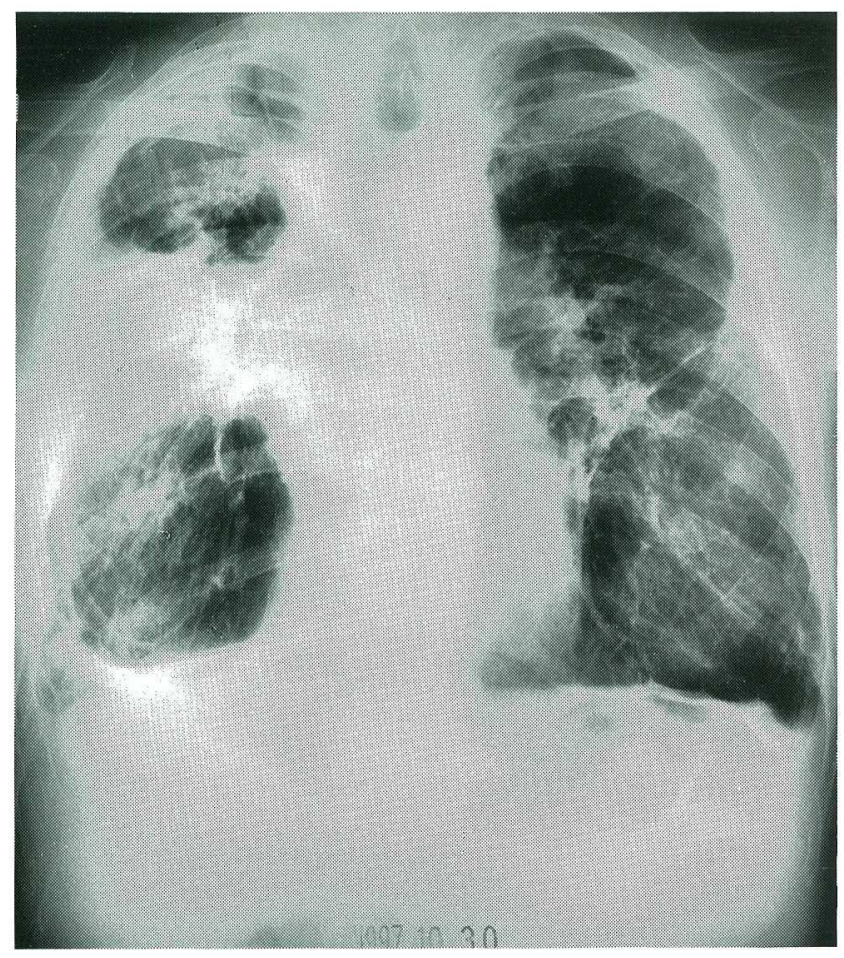

Figure 1. Chest $\mathrm{X}$-ray showing a large band-like shadow extending from the hilum to the right middle lung field.

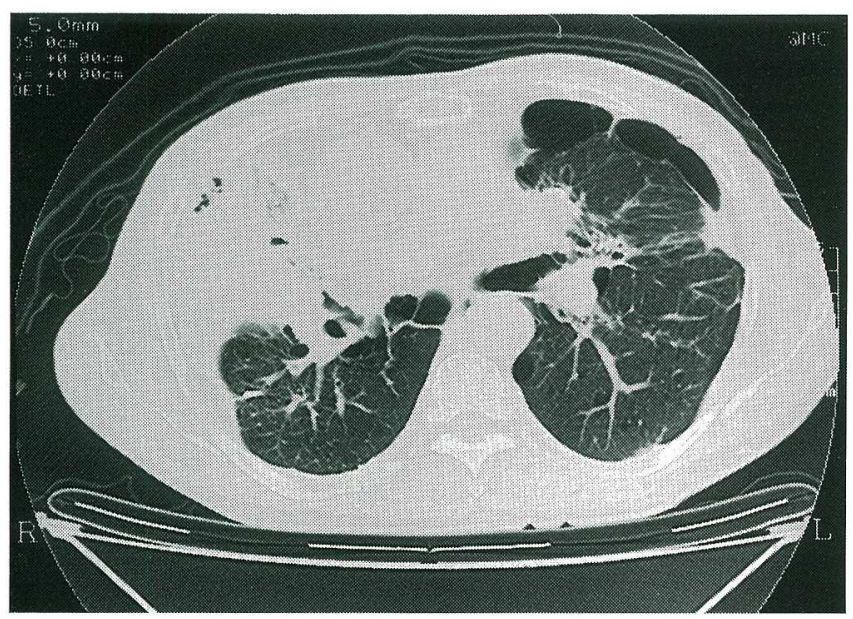

Figure 2. Computed tomography showing atelectasis of the right middle lobe, suggestive of external obstruction by a tumor of the central bronchus.

The base of the polyp was on the outside of the main bronchus of the right middle lobe, and the middle lobe peripheral to the polyp was to a large extent patent. Histopathological examination of tissue specimens obtained from an area close to the base of the tumor revealed severe cell atypia. The polyp was diagnosed as a squamous papilloma with severe dyspla-

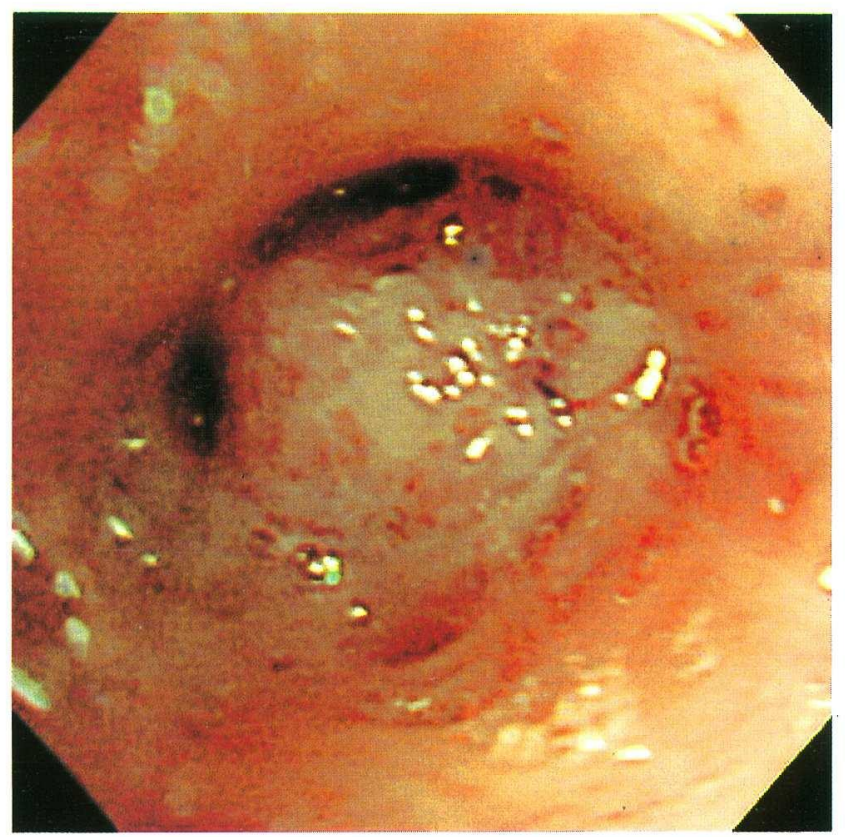

Figure 3. Bronchoscopic view of the bronchus of the right middle lobe showing a polypoid tumor, which was very soft and free of coating, bleeding and ulceration.

sia.

Atelectasis improved following excision of the papilloma by electrosurgical snare, but on subsequent chest CT scans, a solitary tumor, $3 \mathrm{~cm}$ in diameter, was found in the lung, which was adjacent to the external surface of the main bronchus of the middle lobe where the polyp had been located (Fig. 5A). The tumor was suspected to be a lung cancer that had been masked by atelectasis, and percutaneous biopsy of this intrapulmonary tumor was conducted with a 19 gauge Sure-Cut needle under fluoroscopy. Histological examination showed keratinization and necrosis in areas of the intrapulmonary tumor. The pathological diagnosis of this tumor was squamous cell carcinoma (Fig. 5B) and the clinical stage of the lung cancer was one (T2NOM0).

It was considered that surgery and radiotherapy were not indicated in this case because of fibrous adhesions and the state of pulmonary function. Accordingly, chemotherapy with cisplatin, mitomycin $\mathrm{C}$ and vindesine was initiated, which resulted in $>50 \%$ shrinkage of the tumor. Unfortunately, the patient subsequently developed Parkinson's disease as an adverse reaction to chemotherapy, associated with various other complications such as erroneous aspiration. However, the patient gradually improved, and was followed up in the outpatient clinic. At three months after initiation of chemotherapy, the endobronchial soft tumor increased in size again, and malignant changes were observed at the base of the papilloma. 


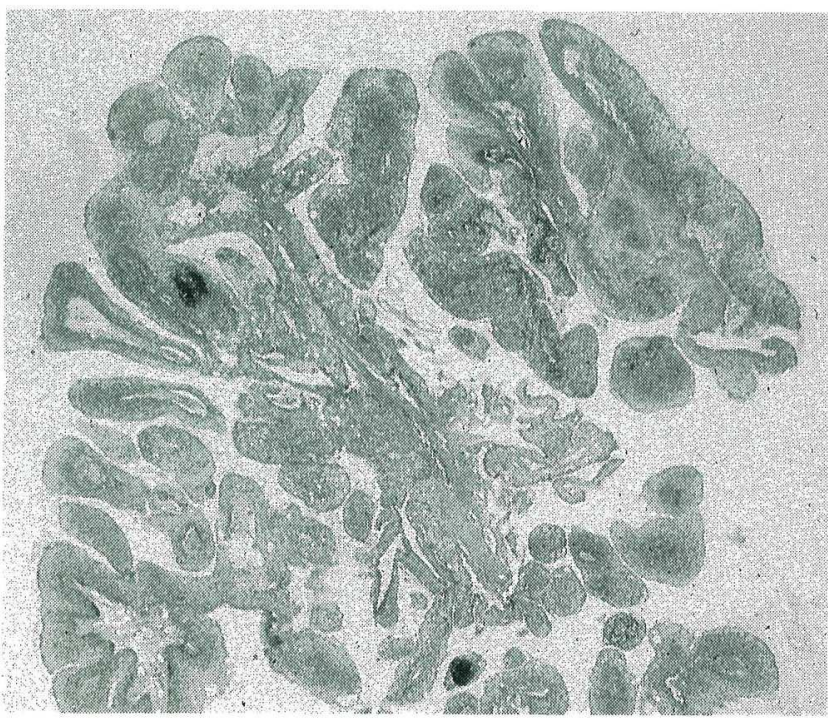

A

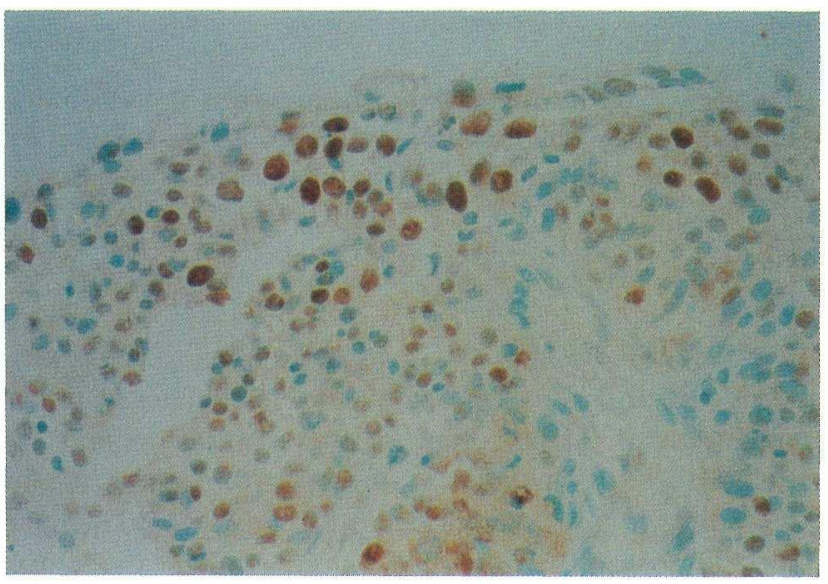

C

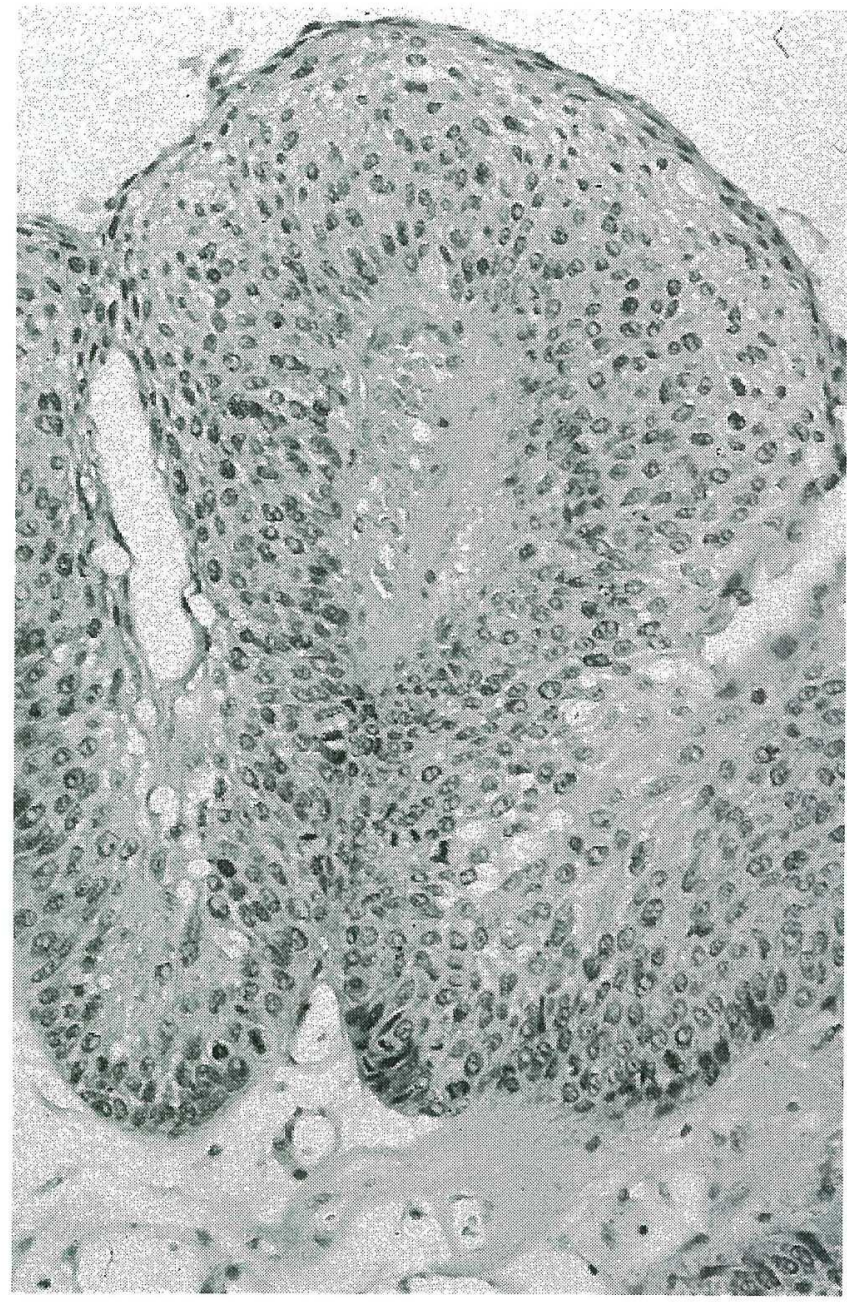

$\mathrm{B}$

Figure 4. Bronchial biopsy showed a papilla-like tumor composed of angiofibrous interstitium and proliferation of stratified squamous epithelium with a tendency for differentiation from the base to the superficial layer $(\mathrm{HE}$ stain, 4A: $\times 2,4 \mathrm{~B}: \times 100)$. P53 immunoreactivity was scattered in the nuclei of stratified squamous epithelium (immunohistochemistry for P53, 4C: $\times 400$ ).

\section{Discussion}

Solitary papilloma, a pedunculated tumor which arises from the normal bronchial epithelium, is mostly found in elderly people. Maxwell et al (3) divided this tumor into two categories; one is defined as solitary papilloma covered with columnar or cuboidal epithelium, with or without squamous metaplasia. The other type consists of solitary squamous papillomas, which have well-formed connective tissue stroma, covered by stratified squamous epithelium.

Solitary bronchial papilloma is relatively rare, and only 38 cases have been reported in Japan, including the present case
(Table 1). The age distribution of the cases is in the range of 22 to 80 years (mean, 58.3 years), and the highest incidence of solitary bronchial papilloma is seen in the 6th decade. The male: female ratio is $3: 2$, indicating male preponderance. The 34 reported cases with full description of symptoms included 24 symptomatic ones. Cough is the commonest presenting symptom, followed by blood-stained sputum. Among 20 cases in whom smoking history was evaluated, 17 were smokers, and 15 of these were heavy smokers (smoking index $>400$ ). Thus, there seems to be a very close relationship between this type of papilloma and smoking habits. Passive smoking also needs to be taken into account in female cases. Most tumors in the reported 36 cases were located in the segmental or more central 


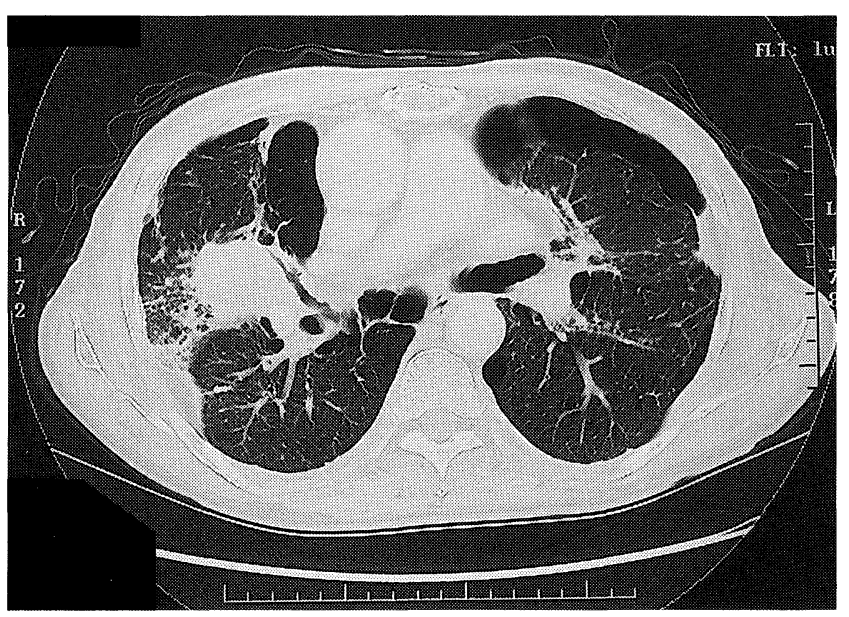

A

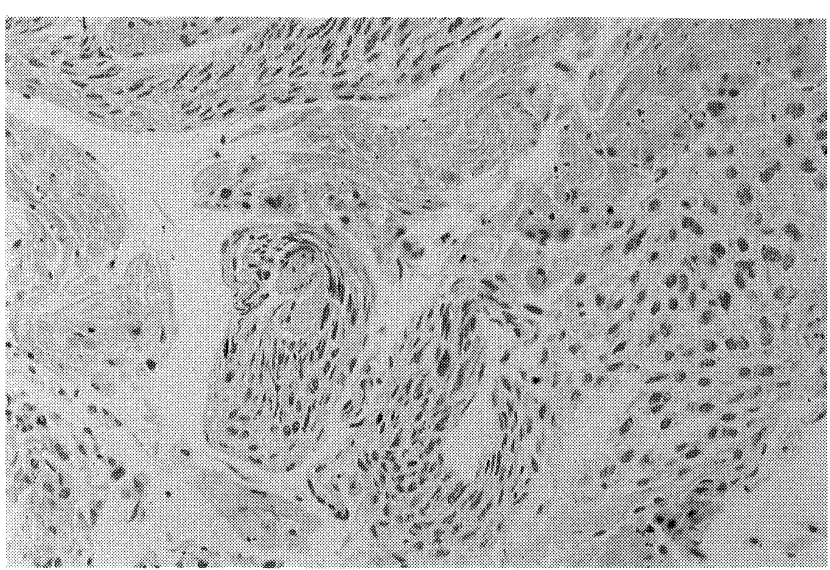

$\mathrm{B}$

Figure 5. (A) On chest CT scan, a tumor, 3-cm in diameter, was found in the lung, which was adjacent to the external surface of the bronchus of the middle lobe where the polyp was located. (B) Histopathological examination showing keratinization and necrosis in areas of the intrapulmonary tumor (HE stain, $\times 100)$. The final diagnosis was squamous cell carcinoma.

Table 1. Solitary Bronchial Papillomas Reported in Japan

$\begin{array}{llc}\text { 1) Age (mean) } & & 22-80 \text { ys (58.3 ys) } \\ \text { 2) Sex } & \text { male } & 29 \\ & \text { female } & 9 \\ \text { 3) Smoking } & (+) & 17 \\ & (-) & 3 \\ \text { 4) Symptom } & (+) & 24 \\ & (-) & 10 \\ \text { 5) Side } & \text { left } & 21 \\ & \text { right } & 15 \\ \text { 6) Location } & \text { central } & 31 \\ & \text { peripheral } & 5 \\ \text { 7) Histological type } & \text { Squamous cell pa. } & 19 \\ & \text { other pa. } & 6 \\ \text { 8) Complication of } & \text { (+) } & 8 \\ \text { lung cancer } & \text { (-) } & 30 \\ \text { 9) Treatment } & \text { Surgical } & 21 \\ & \text { Endoscopic removal } & 8 \\ & \text { Radiation } & 1 \\ & \text { YAG-laser } & 1 \\ & \text { Surgical snare } & 1 \\ & \text { No therapy } & 3\end{array}$

bronchi [31 cases (86\%)], while only five tumors were found in subsegmental or peripheral bronchi. Histologically, the tumors consisted of 19 squamous cell papillomas, and 6 papillomas covered with columnar or cuboidal epithelium. They ranged in size from a minimum of $2 \mathrm{~mm}$ to a maximum size equivalent to a hen egg. Many tumors were grossly described as papillary, granular or tumors with an uneven surface, but no coating, bleeding or ulceration was noted in the reported cases.
Squamous cell carcinomas identified within papillomas show prominent cellular pleomorphism, loss of maturation, increased dyskeratosis and hyperkeratosis, and most importantly, invasion of adjacent lymphatic tissues through the bronchial wall (4). Roviaro et al (5) indicated that malignant changes were observed in three of four solitary papillomas. Among the cases reported from Japan, only three, including the present case, showed malignant changes on autopsy, lobectomy or percutaneous needle biopsy specimens (Table 2) $(6,7)$. The lesion in our case was thought to be a squamous cell carcinoma of the lung that developed at the base of the papilloma, and then invaded the lung through the bronchial wall. Moreover, squamous cell carcinomas were found in other bronchi in five of the cases (8-12). Three squamous cell carcinomas were found in Case 5, and two carcinomas in Case 7. Extrinsic carcinogenic factors affecting the bronchus, including smoking, were the suspected causes in these cases. Roviaro et al (5) suggested that smoking might be the cause of malignant changes in benign neoplasia.

Although surgery was not indicated in our case, it is the most effective treatment. Zimmermann et al (13) reported recurrent papilloma of the bronchus after an incomplete endoscopic resection. Taking into account the fact that there had been only three cases of malignant changes reported from Japan, and the potential spread of cancer to another site in the lung, which might also require resection, lobectomy should be avoided if the tumor can be removed completely by endoscopy (14). For conservation of pulmonary function, segmentectomy or endoscopic resection, if the lesion is small, may be employed, with a close monitoring of the clinical course after such procedure. If the lesion is limited to a small area of the bronchus, conservative treatment, such as photodynamic therapy, yttrium aluminum garnet (YAG) laser vaporization, or electrosurgical 
INOUE et al

Table 2. Solitary Bronchial Papillomas with the Malignant Change or the Complication of Lung Cancer in the Other Lobe in Japan

\begin{tabular}{|c|c|c|c|c|c|c|c|}
\hline Reporter & Age/Sex & Site & Symptom & Chest X-p & Smoking & Treatment & Complication \\
\hline 1. Fujio (1975) (8) & $55 \mathrm{M}$ & rt. middle & $(-)$ & Tumor shadow & 300 & pneumonectomy & Lung ca (lt. S2) \\
\hline 2. Kasamatsu (1985) (6) & $75 \mathrm{M}$ & lt. upper & cough & Infitrative shadow & 1,000 & YAG-laser & Carcinoma in situ \\
\hline 3. Yano (1988) (9) & $75 \mathrm{M}$ & TIM & wheeze & Tumor shadow & - & - & Lung ca (lt. $\mathrm{S} 1+2)$ \\
\hline 4. Katsura (1990) (10) & $58 \mathrm{M}$ & lt. B3 & $(-)$ & Chest abnormal shadow & - & Removed by BF & Lung ca (lt. S8) \\
\hline 5. Hirasawa (1991) (11) & $69 \mathrm{M}$ & lt.B1+2 & cough & Normal & 2,820 & Removed by BF & Triple lung ca \\
\hline 8. Present case & $70 \mathrm{M}$ & rt. middle & cough \& sputum & collapse & 1,410 & $\begin{array}{c}\text { Removed by BF } \\
\text { (surgical snare) }\end{array}$ & Lung ca (rt. middle) \\
\hline
\end{tabular}

snare, seem sufficient to obtain a complete cure. In cases where, as in the present case, cell atypia is severe, the closer the malignant tumor is to the base of papilloma, or in cases where tumor markers, such as SCC-Ag and CYFRA, are already elevated, surgery is the treatment of choice even if no findings suggestive of cancer are present. The electrosurgical snare allows biopsy of the base of tumor and diagnosis, in addition to excision of the tumor, and should therefore be the selected treatment modality rather than YAG laser vaporization.

\section{References}

1) Popper HH, Wirnsberger G, Juttner-Smolle FM, Pongratz MG, Sommersgutter M. The predictive value of human papilloma virus (HPV) typing in the prognosis of bronchial squamous cell papillomas. Histopathology 21: 323-330, 1992.

2) Spencer H, Dail DH, Arneaud J. Non-invasive bronchial epithelial papillary tumors. Cancer 45: 1486-1497, 1980.

3) Maxwell RJ, Gibbons JR, O'Hara MD. Solitary squamous papilloma of the bronchus. Thorax 40: 68-71, 1985.

4) DiMarco AF, Motenegro H, Payne CB Jr, Kwon KH. Papillomas of the tracheobronchial tree with malignant degeneration. Chest 74: 464-465, 1978.

5) Roviaro GC, Varoli F, Pagnini CA. Is the solitary papilloma of the bronchus always a benign tumor? ORL 43: 301-308, 1981.

6) Kasamatsu N, Hashizume I, Shinozaki K, et al. A case of solitary papilloma of the bronchus with an area of carcinoma in situ. Japanese Journal of Lung Cancer 26: 445-451, 1986 (Abstract in English).

7) Tomino H, Sano M, Iizuka M, Yamada K, Yokoyama T, Mizuno T. A case of lung cancer associated with solitary bronchial papilloma. The Journal of the Japan Society for Bronchology 16: 595, 1994 (Abstract in Japanese).

8) Fujio A, Itano T, Kotani S, Nakamichi T, Nonoyama A, Kagawa T. A case of solitary bronchial papilloma associated with pulmonary carcinoma. Nippon Kyobu Rinsho 39: 292-296, 1975 (Abstract in English).

9) Yano M, Mitsuya A, Nishimura T, Ando H, Souma N, Hamasaki Y. A case of solitary bronchial papilloma associated with lung cancer. Nippon Kyobu Shikkan Gakkai Zasshi 26: 1023, 1988 (Abstract in Japanese).

10) Katsura K, Yomo S, Kanbe Y, et al. A case of acanthosis nigricans associated with pulmonary squamous cell carcinoma and solitary bronchial papilloma. The Journal of The Japan Society for Bronchology 12: 311316, 1990 (Abstract in English).

11) Hirasawa M, Honda Y, Fujishima T, Igarashi T, Asakawa M, Suzuki A. A case of solitary papilloma of the bronchus associated with triple tracheobronchial cancers. Japanese Journal of Lung Cancer 31: 403-408, 1991 (Abstract in English).

12) Niitani K, Tsuya $T$, Kitaguchi $S$, et al. A case of multiple lung cancers with a solitary bronchogenic papilloma and laryngeal cancer. The Journal of The Japan Society for Bronchology 17: 40-45, 1995 (Abstract in English).

13) Zimmermann A, Lang HR, Muhlberger F, Bachmann M. Papilloma of the bronchus. Respiration 39: 286-290, 1980.

14) Miura H, Tsuchida T, Kawate N, Konaka C, Kato H, Ebihara Y. Asymptomatic solitary papilloma of the bronchus: review of occurrence in Japan. Eur Respir J 6: 1070-1073, 1993. 